\title{
Rekayasa Augmented Reality Planet dalam Tata Surya sebagai Media Pembelajaran Bagi Siswa SMP Negeri 57 Palembang
}

\author{
Agmita Clara Rosa $^{1)}$, Hastha Sunardi ${ }^{2)}$, Herri Setiawan ${ }^{3)}$ \\ ${ }^{1223)}$ Program Studi Informatika Universitas Indo Global Mandiri \\ Jl. Jend Sudirman No.629 km. 4 Palembang Kode Pos 30129 \\ Email: ochapriyono254@gmail.com ${ }^{1)}, \underline{\text { hastha_s@uigm.ac.id }{ }^{2} \text {, }}, \underline{\text { herri@uigm.ac.id }{ }^{3)}}$
}

\begin{abstract}
Information Technology Utilization in teaching materials is considered very helpful in providing science learning material about the type of solar system, the texture and layers that are inside the planet. Augmented reality technology is combines two-dimensional or 3-dimensional virtual objects into a real three-dimensional environment and then projects virtual objects in real time and takes place simultaneously. Showing material, the application can also display images of planets in $3 D$ animation objects along with planetary layers and practice questions, using text books as markers for augmented reality with marker tracking methods that can be used on android. The method used from this application is the Rational Unified Process and modeling the Unified Modeling Language (UML). Using C\# programming language for coding programs that will be used in making augmented reality. By building a system of simulating the solar system of the planet Bima Sakti as an iteractive learning media for students using an Androidbased augmented reality technology that is effective in providing information about the descriptions of planets and planetary layers, it is hoped that there will be added value for students to get to know the Creator. By knowing how great the universe is, students will certainly be able to understand the vastness of this universe, which of course there will be awareness for students that the Creator of this universe, of course, is greater than his creation and more powerful over his creation. So that the material from this application can be combined with religious studies, especially Islamic Religion.
\end{abstract}

Keywords : Augmented Reality, Solar System. Interactive learning, C \# (C Sharp), RUP

\begin{abstract}
ABSTRAK
Pemanfaatan Teknologi Informasi pada bahan ajar untuk siswa dinilai sangat membantu dalam memberikan materi pembelajaran IPA tentang sistem tata surya jenis, tekstur dan lapisan yang ada didalam planet. Teknologi Augmented Reality adalah teknologi yang mengabungkan benda maya dua dimensi ataupun 3 dimensi kedalam sebuah lingkungan nyata tiga dimensi lalu memproyeksikan benda-benda maya tersebut dalam waktu nyata dan berlangsung bersamaan. Menampilkan materi, aplikasi juga dapat menampilkan gambar planet dalam objek animasi $3 D$ disertai lapisan planet dan latihan soal, menggunakan buku teks sebagai marker untuk augmented reality dengan metode marker tracking yang dapat digunakan diandroid. Metode yang digunakan dari aplikasi ini adalah Rational Unified Process dan pemodelan Unified Modeling Language (UML). Menggunakan bahasa pemrograman C\# untuk coding program yang akan digunakan dalam pembuatan augmentedreality. Dengan membangun system simulasi tata surya planet Bima Sakti sebagai media pembelajaran iteraktif bagi siswa menggunakan teknologi augmented reality berbasis android yang efektif dalam memberikan informasi tentang deskripsi planet dan lapisan planet, diharapkan ada nilai tambah bagi siswa untuk lebih mengenal Sang Pencipta. Dengan mengenal betapa besar jagat raya ini, maka siswa tentunya akan dapat memahami begitu luasnya alam ini, yang tentunya akan ada kesadaran bagi siswa bahwa Sang Pencipta alam raya ini, tentunya lebih besar dari ciptaannya dan lebih berkuasa atas ciptaannya. Sehingga materi dari aplikasi ini dapat dikombinasikan dengan pelajaran agama, khususnya Agama Islam.
\end{abstract}

Kata kunci : Augmented Reality, Tata Surya, Pembelajaran Interaktif, RUP 


\section{Pendahuluan}

Teknologi Augmented Reality dapat di terapkan sebagai sebuah media pembelajaran pengenalan tata surya agar dapat membantu pengguna mendapatkan informasi mengenai tata surya dengan cara yang lebih menarik yaitu dengan menggunakan teknologi. Minat membaca buku pada anak indonesia sangat rendah hanya $0,01 \%$ atau sekitar 10,000 jiwa, dengan bantuan teknologi diharapkan dapat meningkatkan jumlah pembaca buku, khususnya anak-anak. Teknologi mobile device sudah menjadi bagian dari kehidupan masyarakat modern, baik muda maupun tua tidak bisa lepas dari smartphone mereka. Android merupakan jenis Sistem Operasi yang paling popular di smartphone, pada tahun 2015 pengguna Android di indonesia sebanyak 41 juta pengguna (ErlanDarmawan,2018). Sistem yang ada pada saat ini, umumnya siswa mengenal tata surya hanya dari media buku yang didapatkan dari sekolah.

Buku yang digunakan dalam kagiatan belajar tata surya tentu saja menampilkan gambar objek dari anggota tata surya, namun untuk mengenal tata surya akan lebih baik menggunakan sebuah alat peraga seperti planetplanet, matahari dan objek lainnya sebagai sebuah alat pendukung agar dapat lebih baik untuk menyerap pelajaran tata surya (Toufan Diansyah Tambunan, 2016).

Augmented Reality (AR) adalah penggabu-ngan antara objek virtual dengan objek nyata, augmented reality dapat dipublikasikan untuk semua indra, termasuk pendengaran, sentuhan dan penciuman. Selain digunakan dalam bidang-bidang seperti kesehatan, militer, industri manufaktur, augmented reality juga telah diaplikasikan dalam perangkat-perangkat yang digunakan orang banyak, seperti pada smartphone dengan memanfaatkan fitur kamera yang ada di hampir semua smartphone saat ini. Tujuan utama dari augmented reality adalah untuk menciptakan lingkungan baru dengan menggabungkan interaktivitas lingkungan nyata dan virtual secara real time sehingga pengguna merasa bahwa lingkungan yang diciptakan adalah nyata (Susanna Dwi Yulianti Kusuma,2018).

\section{A. Perumusan Masalah}

Berdasarkan latar belakang yang telah dijabarkan diatas maka masalah yang akan dibahas adalah bagaimana cara mensimulisasikan sistem tata surya dalam bentuk aplikasi sebagai media pembelajaran interaktif berbasis android, mengetahui deskripsi, lapisan pada planet dan cara memfasilitasi siswa untuk bermain sambil belajar.

\section{B. Batasan Masalah}

Adapun beberapa batasan masalah dalam penelitian ini, yaitu:

1. Tata surya yang disimulasikan dalam pembelajaran interaktif ini adalah, hanya planet yang ada dalam gugusan Bima Sakti.

2. Marker yang digunakan ada 8 planet dan 1 matahari
3. Membahas tentang deskripsi planet, kandungan unsur atmosfer yang ada di dalam masing-masing planet.

\section{Tujuan dan Manfaat Penelitian}

Adapun tujuan penelitian adalah membangun system simulasi tata surya planet Bima Sakti sebagai media pembelajaran iteraktif bagi Siswa menggunkan teknologi augmented reality berbasis android yang efektif dalam memberikan informasi tentang deskripsi planet, lapisan planet serta dapat digunakan belajar terdapat soal kuis dalam aplikasi tersebut.

\section{Augmented Reality}

Augmented reality yaitu upaya untuk menggabungkan dunia nyata dan dunia virtual yang dibuat melalui komputer sehingga batas antara keduanya menjadi sangat tipis, augmented reality atau biasa disebut dengan AR bukan merupakan teknologi yang baru teknologi ini telah ada hampir 40 tahun yang lalu, setelah diperkenalkan aplikasi Virtual Reality (VR) untuk pertama kalinya. Secara umum augemented reality adalah sebuah teknologi multimedia yang dapat mengabungkan sebuah atau beberapa objek benda maya dua dimensi (2D) ataupun 3 dimensi (3D) ke dalam lingkungan nyata menggunakan kamera Head-Mounted Display (HMD).

Menurut Prita Haryani dan Joko Triyono (2017) Augmented Reality (AR) merupakan salah satu bagian dari Virtual Environment(VE) atau yang biasa dikenal dengan Virtual Reality (VR). AR memberikan gambaran kepada pengguna tentang penggabungan dunia nyata dengan dunia maya dilihat dari tempat yang sama. AR memiliki tiga karakteristik yaitu bersifat interaktif (meningkatkan interaksi dan persepsi pengguna dengan dunia nyata), menurut waktu nyata (real time) dan berbentuk 3 dimensi merupakan penggabungan dunia nyata dan duniamaya.

Marker biasanya dengan warna hitam dan putih cara pembuatanya pun cukup sederhana tapi harus diperhatikan ketebalan marker yang harus dibuat, ketebalan marker jangan kurang daru 25\% dari panjang garis tepi agar pada saat proses deteksi marker dapat lebih akurat (Muhammad Afdal dan Muhammad Irsyad 2018).

Sebuah metode yang memanfatkan marker yang biasanya berupa ilustrasi hitam dan putih berbentuk persegi atau lainya dengan batas hitam tebal dan latar belakang putih. Melalui posisi yang dihadapkan pada sebuah kamera komputer atau smartphone, maka komputer akan melalukukan proses menciptakan virtual $2 \mathrm{D}$ atau 3D.

\section{E. Tata Surya}

Tata surya adalah sebuah kesatuan sistem yang berisi kumpulan benda-benda langit yang terdiri dari matahari dan semua objek yang terikat oleh gaya gravitasinya secara spesifik, dalam tata surya. Kesatuan sistem itu terdiri dari matahari, planet-planet yang berjumlah 8 termasuk bumi, satelit dan masing-masing planet dan 
jutaan benda langit lain (asteroi, meteor dan komet). Matahari berperan sebagai pusat tata surya semua benda langit khususnya planet-planet bergeral mengelilingi matahari sesuai dengan lintasan atau orbit dari planetplanet tersebut terbentuk elips atau oval. Claudius Ptolomeus (100-178 SM) berasal dari Alexandria, adalah orang pertama yang mengemukakan pendapat bahwa bumi sebagai pusat peredaraan tata surya Geocentry System (peredaraan tata surya Geocentry System (AdeRandi, 2017).

\section{F. Media Pembelajaran Interaktif}

Media pembelajaran interaktif adalah sebuah metode pembelajaraan yang memung-kinkan komunikasi antara manusia dan teknologi melalui sistem dan insfastruktur berupa program aplikasi serta pemanfatan media elektronik sebagai dari metode edukasi. Media pembelajaran merupakan alat atau komponen dalam pembela-jaran yang berperan sebagai perantara komunikasi antara guru dengan peserta didik dalam mengirimkan/menyampaikan informasi atau materi (Rahman, 2017).

\section{G. Rational Unified Process (RUP)}

Rational Unified Process (RUP) adalah pendekatan pengembangan perangkat lunak yang dilakukan berulang-ulang (iterative), fokus pada arsitektur lebih diarahkan berdasarkan penggunan kasus (use case driven). RUP merupakan proses rekayasa perangkat lunak dengan pendefisian yang baik (well structured), RUP menyediakan pendefinisian struktur yang baik untuk alur hidup proyek perangkat lunak. RUP merupakan sebuah tahapan pengembangan sitem secara iteratif khusus untuk pemrograman berorientasi objek (PBO). Menurut Rosa A. Sukamto (Rekayasa Perangkat Lunak Rational Unified Process 2013:124) sebuah produk proses perangkat lunak yang dikembangkan oleh Rational Software yang diakusisi oleh IBM di bulan Februari 2003. Memiliki fase-fase untuk setiap tahapan dalam Model RUP (Rational Unified Process), yaitu :

1. Inception

Tahap ini lebih pada memodelkan proses bisinis yang dibutuhkan dan mendefinisikan kebutuhan akan sistem yang akan dibuat.

Elaboration

Tahap ini lebih difokuskan pada perencanaan arsitektur sistem dan tahap ini juga dapat mendeteksi apakah arsitektur sistem yang diinginkan dapat dibuat atau tidak.

2. Construction

Tahap ini fokus pada pengembangan komponen dan fitur-fitur sistem dan tahap ini lebih pada implementasi dan pengujian sistem yang fokus pada implemntasi perangkat lunak pada kode program

3. Transition

Tahap ini lebih pada deployment atau instalasi sistem agar dapat dimengerti oleh user dan tahap ini mengahasilkan produk perangkat lunak dimana menjadi syarat initial Operational Capability Milestore atau batas tongkak kemampuan awal.

\section{H. Unified Modeling Language (UML)}

Menurut RosaA. Sukamto (RekayaPerangkat Lunak Terstruktur dan Berorientasi 2013:137) Unified Modeling Language (UML) adalah bahasa visual untuk permodelan dan komunikasi mengenai sebuah sistem dengan menggunakan diagram.

Unified Modeling Language (UML) merupa-kan sistem arsitektur yang bekerja dalam OOAD (OjectOriented Analysis/Design) dengan satu bahasa yang konsisten menentukan visualisasi, mengkontruksidan mendokumen- tasikan artifact (sepotong informasi yang digunakan atau dihasilkan dalam suatu proses rekayasa software dapat berupa model, deskripsi atau software) yang terdapat dalam sistem software. UML merupakan bahasa pemrograman yang paling sukses dari tiga metode OO yang telah ada sebelumnya, yaitu Booch,OMT (Object Modeling Technique) dan OOSE (Object Oriented Software Engineering).

\section{Pembahasan}

Metode pengembangan sistem yang digunakan dalam membangun aplikasi Rekayasa Augmented Reality Tata Surya Sebagai Media Pembelajaran Siswa SMP adalah Metode Rational Unified Process (RUP). Tahap identifikasi adalah tahap interface untuk aplikasi yang didukung dengan observasi atau wawancara langsung kepada user. Penelitian dilakuan di SMP Negeri 57 Palembang. Objek penelitian ini adalah alas an kenapa siswa kurang memahami belajar mengenaisistem tata surya karena kurangnya alat peraga yang diguna-kan oleh guru dalam menerangkan pelajar-an. Gambar use case pada aplikasi Rekayasa Augmented Reality Tata Surya Sebagai Media Pembelajaran Siswa SMP pada penelitian ini dilihat pada Gambar 1.

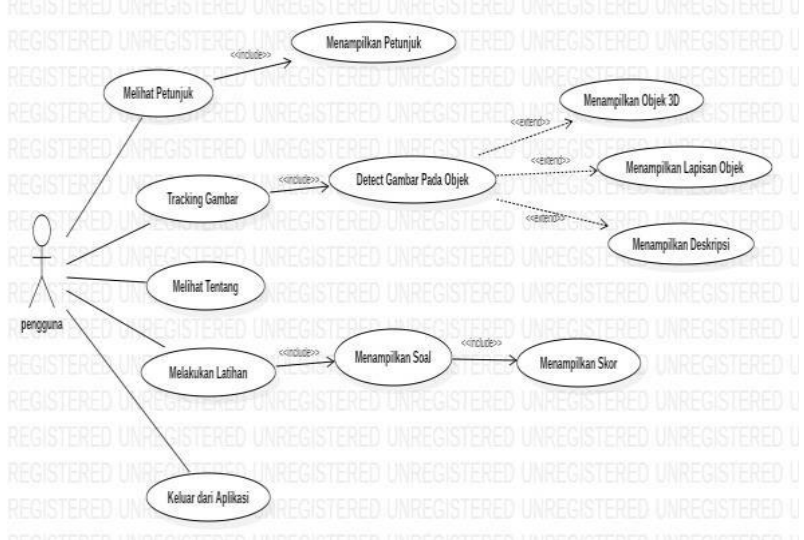

Gambar 1. Diagram Use Case

Berikut ini adalah hasil dari implementasi aplikasi Rekayasa Augmented Reality Tata Surya Sebagai Media Pembelajaran Siswa SMP pada emulator Android di Android Studio pada Smartphone.

\section{A. Antarmuka Halaman Menu Utama}

Pada halaman menu utama terdapat 5 tombol button yaitu tombol petunjuk berisikan cara menggunakan 
aplikasi tersebut, tombol mulai digunakan untuk metracking gambar dengan marker yang telah terintergrasi oleh augmented Reality, tombol tentang berisi tentang biodata pembuat aplikasi, tombol latihan berisi soal materi yang digunakan siswa untuk belajar dan tombol keluar berisi pesan untuk keluar dari aplikasi tersebut.

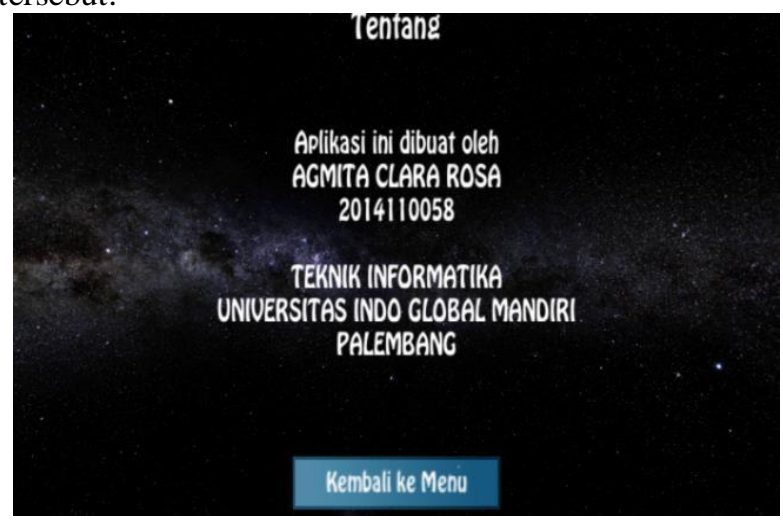

Gambar 2. Antarmuka menu utama

\section{B. Antarmuka Halaman Menu Petunjuk}

Dalam antarmuka menu petunjuk terdapat 2 tombol aksi, yaitu petunjuk selanjutnya dan kembali ke menu.

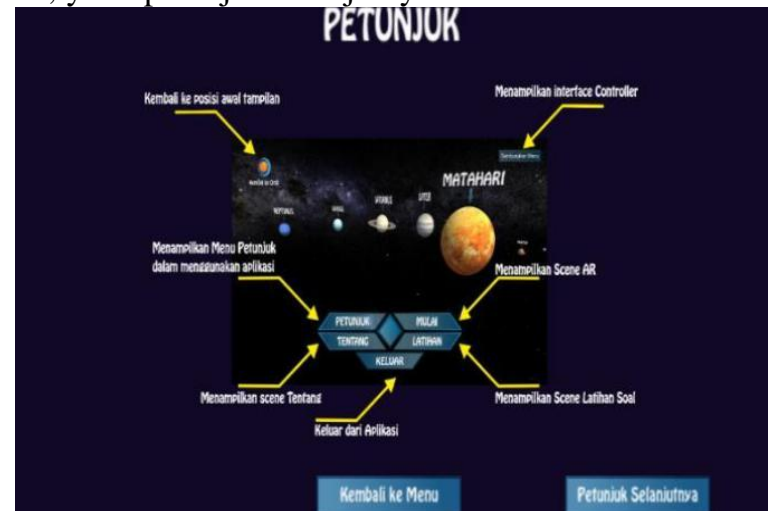

Gambar 3. Antarmuka menu Petunjuk

\section{Antarmuka Halaman Menu Tentang}

Dalam menu tentang terdapat 1 tombol aksi kembali kemenu, berisi informasi mengenai penulis tampilan menu tentang pembuat aplikasi tersebut.

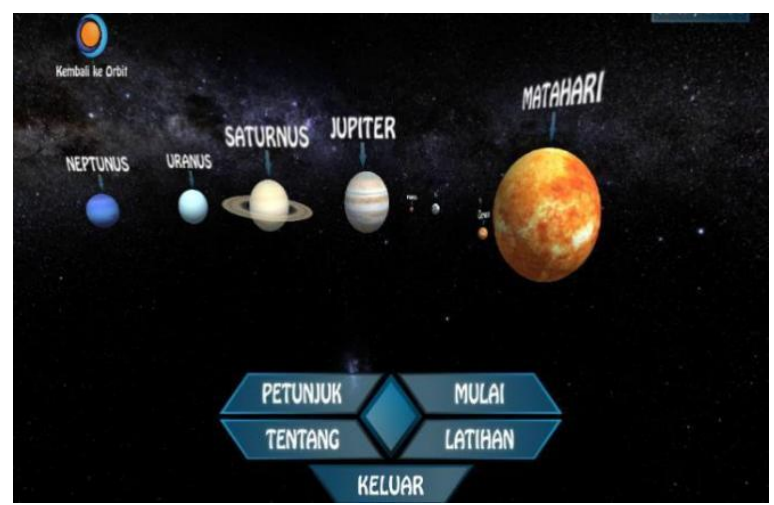

Gambar 4. Antarmuka menu Tentang

\section{Antarmuka Halaman Menu Latihan}

Dalam antar muka menu latihan terdapat 2 tombol aksi, terdiri dari tombol kembali dan lanjut dan berisi soal-soal materi tentang planet tata surya. Jika pengguna bisa menjawab soal maka akan mendapatkan poin namun jika jawaban salah maka sistem akan menampilkan jawaban yang benar. Sehingga hasil akhir akan keluar berapa poin yang didapat pengguna.

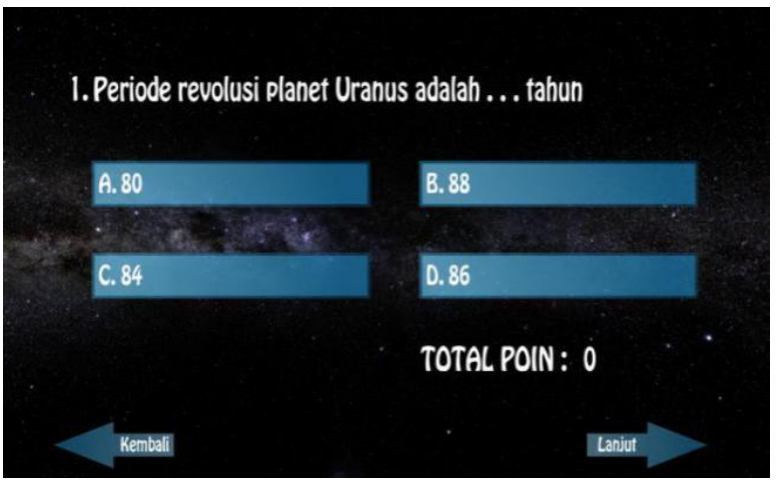

Gambar 5. Antarmuka menu Latihan

E. Antarmuka Augmented Reality Objek 3D

Dalam antar muka ini, akan ditampilkan objek 3D planet tata surya yaitu planet merkurius dengan qrcode sebagai marker dalam penampilan augmented reality berbentuk 3 dimensi.

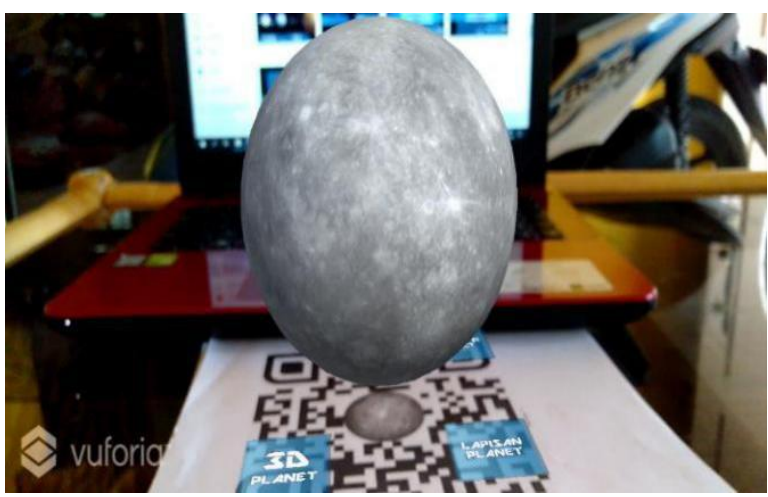

Gambar 6. Antarmuka Augmented Reality Objek

F. Antarmuka Augmented Reality Planet Merkurius

Dalam antar muka ini, akan ditampilkan objek 3D isi dari lapisan planet merkurius dengan qrcode sebagai marker dalam penampilan augmented reality.

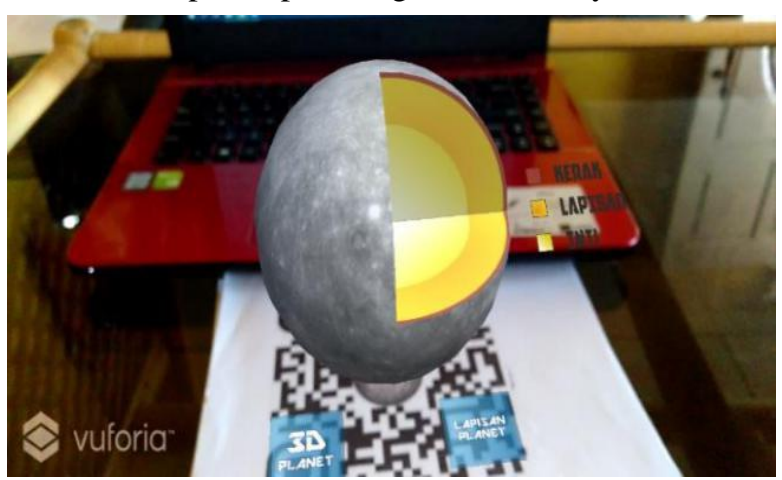

Gambar 7. Antarmuka Augmented Reality Lapisan Planet Merkurius 
G. Antarmuka Augmented Reality Planet Merkurius

Dalam antarmuka ini, akan ditampilkan objek 3D deskripsi planet merkurius dengan qrcode sebagai marker dalam penampilan augmented reality.

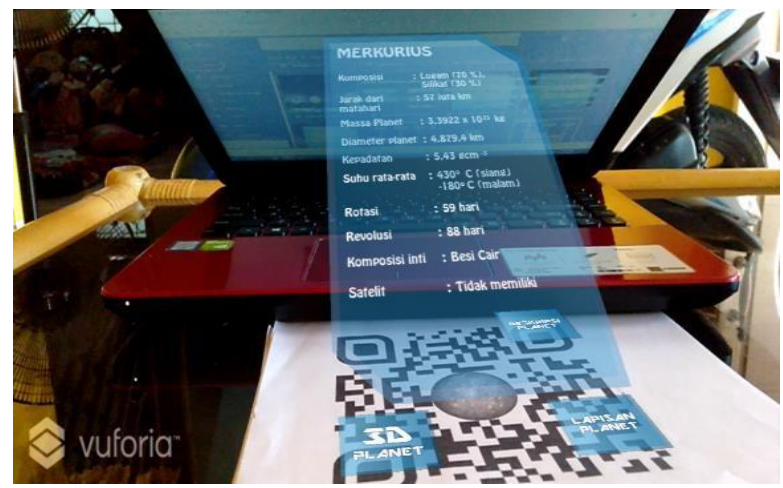

Gambar 8. Antarmuka Augmented Reality Deskripsi Planet Merkurius

Pengujian dilakukan dengan menggunakan Metode Black Box, melalui dua tahapan yaitu menguji sistem secara alpha dan beta, yaitu, dilakukan pengujian terhadap fungsi-fungsi yang tidak benar atau hilang, kesalahan interface, kesalahan dalam struktur data dan kesalahan kinerja. Dimana tujuan akhir hasil pengujian black box dapat dilihat pada tabel- tabel dibawah ini.

Tabel 1. Hasil Pengujian Menu Utama

\begin{tabular}{|c|c|c|l|}
\hline Kelas Uji & Skenario Uji & $\begin{array}{c}\text { Hasil yang } \\
\text { diharapkan }\end{array}$ & Validasi \\
\hline & $\begin{array}{c}\text { Memilih Menu } \\
\text { Mulai }\end{array}$ & $\begin{array}{c}\text { Menampilkan } \\
\text { kamera yang } \\
\text { terinteg oleh } \\
\text { AR }\end{array}$ & Berhasil \\
\cline { 2 - 4 } Menu & $\begin{array}{c}\text { Memilih Menu } \\
\text { Latihan }\end{array}$ & $\begin{array}{c}\text { Menampilkan } \\
\text { halaman latihan } \\
\text { Stama }\end{array}$ & Berhasil \\
\cline { 2 - 4 } & $\begin{array}{c}\text { Memilih Menu } \\
\text { Petunjuk }\end{array}$ & $\begin{array}{c}\text { Menampilkan } \\
\text { halaman menu } \\
\text { petunjuk }\end{array}$ & Berhasil \\
\cline { 2 - 5 } & $\begin{array}{c}\text { Memilih } \\
\text { Menu Tentang }\end{array}$ & $\begin{array}{c}\text { Menamilkan } \\
\text { halaman menu } \\
\text { tentang }\end{array}$ & Berhasil \\
\cline { 2 - 5 } & $\begin{array}{c}\text { Meluar dari } \\
\text { Memilih }\end{array}$ & Berhasil \\
\cline { 2 - 5 } & Menu Keluar & Berhasil & \\
\hline
\end{tabular}

Tabel 2. Hasil Pengujian Menu Tentang

\begin{tabular}{|c|c|c|c|}
\hline Kelas Uji & Skenario Uji & $\begin{array}{c}\text { Hasil yang } \\
\text { diharapkan }\end{array}$ & Validasi \\
\hline $\begin{array}{c}\text { Menu } \\
\text { Tentang }\end{array}$ & $\begin{array}{c}\text { Memilih Menu } \\
\text { Tentang }\end{array}$ & $\begin{array}{c}\text { Menampilkan } \\
\text { halaman tentang } \\
\text { Biografi pembuat }\end{array}$ & Berhasil \\
\hline
\end{tabular}

Tabel 3. Hasil Pengujian Menu Tentang

\begin{tabular}{|c|c|c|c|}
\hline Kelas Uji & Skenario Uji & $\begin{array}{l}\text { Hasil yang } \\
\text { diharapkan }\end{array}$ & Validasi \\
\hline $\begin{array}{c}\text { Menu } \\
\text { Tentang }\end{array}$ & $\begin{array}{l}\text { Memilih } \\
\text { Menu } \\
\text { Tentang }\end{array}$ & $\begin{array}{c}\text { Menampilkan } \\
\text { halaman tentang } \\
\text { Biografi } \\
\text { pembuat }\end{array}$ & Berhasil \\
\hline
\end{tabular}

Tabel 4 . Hasil Pengujian Menu Latihan

\begin{tabular}{|c|c|c|c|}
\hline $\begin{array}{c}\text { Kelas } \\
\text { Uji }\end{array}$ & Skenario Uji & $\begin{array}{c}\text { Hasil yang } \\
\text { diharapkan }\end{array}$ & Validasi \\
\hline Menu & $\begin{array}{c}\text { Memilih } \\
\text { Menu } \\
\text { Latihan }\end{array}$ & $\begin{array}{c}\text { Menampilkan } \\
\text { Soal latihan }\end{array}$ & Berhasil \\
\cline { 2 - 4 } & $\begin{array}{c}\text { Menjawab } \\
\text { Soal }\end{array}$ & $\begin{array}{c}\text { Menampilkan } \\
\text { point yang jika } \\
\text { berhasil } \\
\text { menjawab soal }\end{array}$ & Berhasil \\
\hline
\end{tabular}

Tabel 5. Hasil Pengujian Menu Tracking Gambar

\begin{tabular}{|c|c|c|c|}
\hline Kelas Uji & Skenario Uji & $\begin{array}{l}\text { Hasil yang } \\
\text { diharapkan }\end{array}$ & Validasi \\
\hline \multirow{3}{*}{$\begin{array}{l}\text { Menu } \\
\text { Mulai }\end{array}$} & $\begin{array}{c}\text { Memilih } \\
\text { Menu Mulai }\end{array}$ & $\begin{array}{c}\text { Menampilkan } \\
\text { kamera yang } \\
\text { terintrgrasi } \\
\text { oleh AR }\end{array}$ & Berhasil \\
\hline & $\begin{array}{c}\text { Tracking } \\
\text { gambar } \\
\text { padamarker }\end{array}$ & $\begin{array}{c}\text { Medeteksi } \\
\text { marker yang } \\
\text { telah vald } \\
\text { dengan database } \\
\text { yang } \\
\text { ada }\end{array}$ & Berhasil \\
\hline & $\begin{array}{l}\text { Tombol } \\
\text { Virtual } \\
\text { Button }\end{array}$ & $\begin{array}{c}\text { Menampilkan } \\
\text { gambar } \\
\text { berbentuk } \\
\text { objek3D }\end{array}$ & Berhasil \\
\hline
\end{tabular}

Tabel 6. Pengujian Terhadap Jarak

\begin{tabular}{|c|c|c|c|c|c|c|c|c|}
\hline \multirow{2}{*}{ Marker } & \multirow{7}{*}{ Jarak Deteksi (cm) } \\
\cline { 2 - 9 } & 5 & 1 & 3 & 5 & 7 & 9 & 1 & 1 \\
& & 0 & 0 & 0 & 0 & 0 & 0 & 2 \\
& & & 0 \\
\hline Merkurius & $£$ & $£$ & $£$ & $£$ & $£$ & $£$ & $£$ & $£$ \\
\hline Venus & $£$ & $£$ & $£$ & $£$ & $£$ & $£$ & $£$ & $£$ \\
\hline Bumi & $£$ & $£$ & $£$ & $£$ & $£$ & $£$ & $£$ & $£$ \\
\hline Mars & $£$ & $£$ & $£$ & $£$ & $£$ & $£$ & $£$ & $£$ \\
\hline Jupiter & $£$ & $£$ & $£$ & $£$ & $£$ & $£$ & $£$ & $£$ \\
\hline Saturnus & $£$ & $£$ & $£$ & $£$ & $£$ & $£$ & $£$ & $£$ \\
\hline Uranus & $£$ & $£$ & $£$ & $£$ & $£$ & $£$ & $£$ & $£$ \\
\hline Neptunus & $£$ & $£$ & $£$ & $£$ & $£$ & $£$ & $£$ & $£$ \\
\hline Matahari & $£$ & $£$ & $£$ & $£$ & $£$ & $£$ & $£$ & $£$ \\
\hline
\end{tabular}


Tabel 7. Hasil Pengujian Terhadap Waktu Pengenalan Marker

\begin{tabular}{|c|c|c|c|}
\hline Smartphone & Spesifikasi & Hasil & Waktu \\
\hline $\begin{array}{l}\text { Xiomi MiA1 } \\
\text { (Nougat) }\end{array}$ & $\begin{array}{l}\text { Snapdragon 625, } \\
\text { RAM 4GB, } \\
\text { Kamera belakang } \\
12 \mathrm{MP}\end{array}$ & Berhasil & $\begin{array}{l}0.052 \\
\text { detik }\end{array}$ \\
\hline $\begin{array}{l}\text { Oppo A3S } \\
\text { (Oreo) }\end{array}$ & $\begin{array}{c}\text { Qualcomm } \\
\text { Snapdragon, RAM } \\
\text { 3GB, Kamera } \\
\text { belakang 13MP + } \\
\text { 2MP } \\
\end{array}$ & Berhasil & $\begin{array}{l}0.040 \\
\text { detik }\end{array}$ \\
\hline
\end{tabular}

Tabel 8 Hasil Pengujian Terhadap Pencahayaan

\begin{tabular}{|c|c|c|c|}
\hline \multirow{4}{*}{$\begin{array}{c}\text { Sumber } \\
\text { Cahaya }\end{array}$} & Kondisi & \multicolumn{2}{|c|}{$\begin{array}{c}\text { Marker } \\
\text { Menampilkan } \\
\text { objek 3D }\end{array}$} \\
\cline { 2 - 4 } & Berhasil & Gagal \\
\hline $\begin{array}{c}\text { Siang hari } \\
\text { dengan cahaya } \\
\text { matahari }\end{array}$ & $\begin{array}{c}\text { Dalam } \\
\text { Ruangan }\end{array}$ & 9 & 0 \\
\cline { 2 - 4 } & $\begin{array}{c}\text { Luar } \\
\text { Ruangan }\end{array}$ & 9 & 0 \\
\hline \multirow{2}{*}{$\begin{array}{c}\text { Malam dengan } \\
\text { Pencahayaan }\end{array}$} & $\begin{array}{c}\text { Dalam } \\
\text { Ruangan }\end{array}$ & 9 & 0 \\
\cline { 2 - 4 } & $\begin{array}{c}\text { Luar } \\
\text { Ruangan }\end{array}$ & 9 & 0 \\
\hline \multirow{2}{*}{$\begin{array}{c}\text { Dalam } \\
\text { Rualam tanpa }\end{array}$} & $\begin{array}{c}\text { Luar } \\
\text { Bantuan Lampu }\end{array}$ & 0 & 9 \\
\cline { 2 - 4 } & Ruangan & 0 & 9 \\
\hline
\end{tabular}

Tabel 9. Pengujian Terhadap Deteksi Sudut

\begin{tabular}{|c|c|}
\hline Besar Sudut & Hasil \\
\hline $0^{0}$ & Tidak berhasil medeteksi marker \\
\hline $45^{0}$ & Berhasil medeteksi marker \\
\hline $90^{0}$ & Berhasil medeteksi marker \\
\hline $135^{0}$ & Berhasil medeteksi marker \\
\hline $180^{0}$ & Tidak berhasil medeteksi marker \\
\hline
\end{tabular}

Pengujian menggunakan kuesioner merupakan pengujian secara objektif, dilakukan pengujian secara langsung terhada[ pengguna Responden dalam hal ini yaitu Siswa-Siswi SMP Negeri 57 Palembang kelas 7 dan 2 Guru IPA berjumlah 75 orang jumlah pertanyaan didalam kuesioner berjumlah 8 pertanyaan yang tersebut sudah cukup mewakili tujuan perencanaan aplikasi ini. Pertanyaan yang diajukan dalam kuesioner untuk pengguna aplikasi ini adalah sebagai berikut:

1. Apakah belajar sistem pengenalan tata surya dengan sistem penunjang buku, anda merasa bosan?

2. Aplikasi ini memiliki tampilan yang menarik?

3. Aplikasi ini mudah untuk digunakan?
4. Petunjuk cara menggunakan aplikasi ini mudah untuk dipahami?

5. Deskripsi objek planet dan lapisan planet pada aplikasi ini jelas?

6. Bentuk objek 3D hampir menyerupai aslinya?

7. Menurut anda, apakah aplikasi menggunakan teknologi augmented reality dibutuhkan untuk pembelajaran interaktif di sekolah?

8. Aplikasi ini membantu guru dalam menyampaikan materi kepada siswa yang lebih menarik?

Berdasarkan kuesioner terhadap pegguna aplikasi ini, diperoleh hasil sebanyak $629 / 8=79 \%$, maka untuk rata-rata nilai skor akhir 79 termasuk dalam kategori setuju sehingga dapat disimpulkan bahwa responden sangat setuju dengan adanya aplikasi augmented reality dalam sistem tata surya sebagai media pembelajaran interaktif berbasis android.

\section{Kesimpulan}

Berdasarkan hasil implementasi dan hasil uji coba dari pembuatan aplikasi ini, dapat diambil kesimpulan sebagai berikut:

1. Aplikasi pembelajaran interaktif dengan menggunakan teknologi Augmented Reality berdampak positif bagi siswa SMP Negeri 57. Mempermudah guru menjelaskan kepada siswa dan lebih mendekatkan guru kepada siswa karena saling belajar menggunakan aplikasi yang baru bagi mereka.

2. Berdasarkan berbagai hasil pengujian pada aplikasi museum didapatkan kesimpulan sebagai berikut :

a. Dengan jarak antara $30-100 \mathrm{~cm}$, marker berukuran $12 \times 15 \mathrm{~cm}$ dapat dideteksi dengan baik.

b. Dengan berbagai jenis spesifikasi smartphone yang dipasang aplikasi augmented reality planet menghasilkan perbedaan pada kecepatan respon deteksi marker, semakin besar kapasitas RAM yang digunakan, semakin cepat deteksi marker pada aplikasi.

c. Dalam pendeteksian dengan cahaya yang minim, marker tidak dapat terdeteksi, sedangkan dengan cahaya yang cukup, marker terdeteksi denganbaik.

d. Dengan sudut kemiringan 45 derajat hingga 135 derajat aplikasi masih mendeteksi marker dan menampilkan objek augmented reality.

e. Pada tahap pengujian dengan memberi-kan penghalang pada marker yang menutupi hingga $50 \%$ area marker, aplikasi masih medeteksi marker dan menampilkan objek augmented reality.

\section{Saran}

Berdasarkan kesimpulan yang telah diuraikan, maka perlu tindaklanjut sebagai berikut:

1. Diharapkan kedepannya bagi yang ingin mengembangkan aplikasi ini untuk dapat 
dikembangkan lagi agar dapat diguanakn untuk semua siswa SMP dari kelas 7 s/d kelas 9 untuk mata pelajaran IPA dan menambahkan banyak objek 3D lebih banyak.

2. Mengembangkan aplikasi ini ke platform selain Android. Agar dapat digunakan keseluruh pengguna smartphone

\section{Daftar Pustaka}

Haryani, Prita, and Joko Triyono. 2017. Augmented Reality (AR) Sebagai Teknologi Interaktif Dalam Pengenalan Benda Cagar Budaya Kepada Masyarakat, 7-12.

Hermawan, Latius, and Mochamad Hariadi. 2015. "Pemanfaatan Augmented Reality Sebagai Media Informasi Kampus Menggunakan Brosur." Sentika 2015 (Sentika): 81-88.

Maryuliana, Imam Much Ibnu Subroto, and Sam Farisa Chairul Haviana. 2016. "Sistem Informasi Angket Pengukuran Skala Kebutuhan Materi Pembelajaran Tambahan Sebagai Pendukung Pengambilan Keputusan Di Sekolah Menengah Atas Menggunakan Skala Likert" 1 (2): 1-12.

Randi, Ade. 2017. "Pemanfaatan Teknologi Virtual Reality Sebagai Media Pembelajaran Interaktif Untuk Sistem Tata Surya Berbasis Android."

Rosyad, Prima. 2014. "Pengenalan Hewan Augmented Reality Berbasis Android." Universitas Muhammadiah Surakarta. Universitas Muhammadiyah Surakarta. http://eprints.ums.ac.id/32316/12/naskah publikasi.pdf.

Sartika, Yuni, Toufan Diansyah Tambunan, and Patrick Adolf Telnoni. 2016. “Aplikasi Pembelajaran Tata Surya Untuk IPA Kelas 6 Sekolah Dasar Menggunakan Augemented Reality Berbasis Android." E-Proceeding Of Applied Science 2 (3): 895. https://doi.org/10.1117/12.550069.

Rosa A, and M Shahaludin. 2015. Rekayasa Perangkat Lunak Terstruktur dan Berorientasi .Informatika. Bandung

Wahyutama, F, F Samopa, and H Suryotrisongko. 2013. "Penggunaan Teknologi Augmented Reality Berbasis Barcode Sebagai Sarana Penyampaian Infromasi Spesifikasi Dan Harga Barang Yang Interaktif Berbasis Android, Studi Kasus Pada Toko ABC Surabaya.” Teknik ITS, A481-86. 